\title{
Article
}

\section{Home-Based Exercise And People With Parkinson's Disease: A Systematic Review}

\author{
Hare, Marianne, Hill, James Edward and Clegg, Andrew \\ Available at http://clok.uclan.ac.uk/35449/ \\ Hare, Marianne, Hill, James Edward ORCID: 0000-0003-1430-6927 and Clegg, \\ Andrew ORCID: 0000-0001-8938-7819 (2020) Home-Based Exercise And \\ People With Parkinson's Disease: A Systematic Review. British Journal of \\ Neuroscience Nursing, 16 (5). pp. 230-232. ISSN 1747-0307
}

It is advisable to refer to the publisher's version if you intend to cite from the work. 10.12968/bjnn.2020.16.5.230

For more information about UCLan's research in this area go to http://www.uclan.ac.uk/researchgroups/ and search for <name of research Group>.

For information about Research generally at UCLan please go to http://www.uclan.ac.uk/research/

All outputs in CLoK are protected by Intellectual Property Rights law, including Copyright law. Copyright, IPR and Moral Rights for the works on this site are retained by the individual authors and/or other copyright owners. Terms and conditions for use of this material are defined in the policies page.

\section{CLoK}

Central Lancashire online Knowledge www.clok.uclan.ac.uk

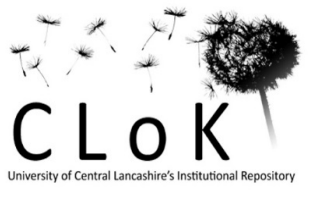




\section{Home-based prescribed exercise improves balance-related activities in people with Parkinson's disease and has benefits similar to centre- based exercise: a systematic review.}

Commentary on: Flynn A, Allen NE, Dennis S, Canning CG, Preston E. Home-based prescribed exercise improves balance-related activities in people with Parkinson's disease and has benefits similar to centre-based exercise: a systematic review. Journal of Physiotherapy. 2019;65(4):189-99.

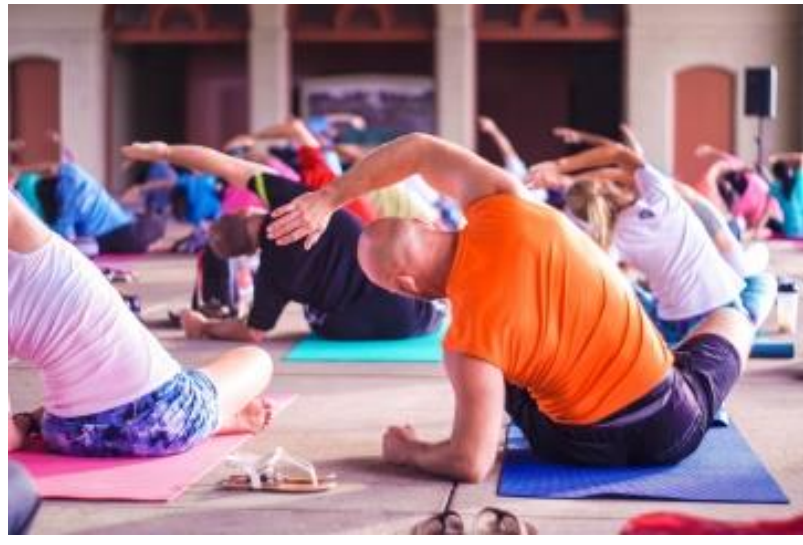

\section{Background to the review}

Parkinson's disease is a neurodegenerative condition, the prevalence of which increases in later life (Sveinbjornsdottir 2016; Parkinson's UK 2017). It is often characterised by slowness of movement, rigidity, tremor and postural and gait impairment (Sveinbjornsdottir 2016). There are also significant non-motor characteristics (Kalia and Lang 2015; Tysnes and Storstein 2017). Pharmacological treatments have been shown to help to manage symptoms of the disease (Kalia and Lang 2015). However, other secondary effects such as postural instability and falls respond poorly to medication (Bronte-Stewart et al. 2002). Previous research has shown that exercise can improve balance (Shen et al. 2016), mobility (Tomlinson et al. 2012), and quality of life (Goodwin et al. 2008) as well as reducing falls (Canning et al. 2015) for adults with Parkinson's disease. Two previous systematic reviews have suggested that the location of delivery can impact the effectiveness of exercise for these outcomes (Shen et al. 2016; Klamroth et al. 2016), with both reviews finding no evidence that home-based exercise can help to improve balance. However, these findings should be viewed with some caution, as both reviews explored the moderator of location via subgroup analysis and did not carry out a specific search for
KEY POINTS

- Home-based exercise can improve balance related activities and gait speed.

- Home-based exercise may be as effective as centre-based exercise for improvement in balance activities for adults with Parkinson's disease.

- High intensity home-based exercise is effective but there is still uncertainty around the effectiveness of low intensity exercise.

this evidence, which may have resulted in important studies being missed.

\section{Aims of the commentary}

This commentary aims to critically appraise the methods used within the systematic review of Flynn et al (2019) and expand upon the findings in the context of clinical practice.

\section{The review}

The aim of the review by Flynn et al (2019) was to explore if home-based exercise improves balance activities and quality of life compared to no intervention or centre-based exercise.

A focused multi-database search was carried out in April 2019 (CENTRAL, CINAHL, EMBASE, and PEDro) with no date or language restrictions. All included trials' reference lists which were searched for additional papers. A robust screening and data extraction process were carried out by two independent reviewers with a third reviewer helping to resolve any discrepancies if consensus was unable to be achieved. 
An appropriate set of inclusion criteria based on the aims of the review where applied. Only randomised and quasi-randomised controlled trials which included adults diagnosed with Parkinson's disease receiving home-based exercise targeting gait and/or standing balance compared to usual care, placebo or centre-based exercise were included. The exercise programmes needed to be delivered by a physiotherapist or a health professional with a degree qualification. The primary outcome of interest was balance related activities. The secondary outcomes which were assessed were gait speed, Berg Balance scale, Functional Reach test and quality of life (QOL). Methodological quality of the included trials was assessed using the physiotherapist evidence database (PEDro) score (Maher et al. 2003).

\section{Quality of the review}

Using the Measurement Tool to Assess systematic Reviews 2 tool (Amstar2) it was judged that this systematic review provides an accurate summary of the trials included in the review (Amstar2 classification: high confidence) (Shea et al. 2017). See Table 1 for full criteria.

Table 1: Amstar2 tool assessment

\begin{tabular}{|l|c|}
\hline \multicolumn{1}{|c|}{ Critical appraisal criteria } & $\begin{array}{c}\text { Criteria } \\
\text { achieved } \\
\text { Yes / No }\end{array}$ \\
\hline Components of PICO & Yes \\
\hline Full detailed protocol used & Yes \\
\hline Explanation of study type & Yes \\
\hline $\begin{array}{l}\text { Comprehensive literature review } \\
\text { strategy }\end{array}$ & Yes \\
\hline Duplicate study selection & Yes \\
\hline Duplicate data extraction & Yes \\
\hline List of excluded studies & Yes \\
\hline $\begin{array}{l}\text { Adequate description of included } \\
\text { studies }\end{array}$ & No \\
\hline $\begin{array}{l}\text { Satisfactory assessment of risk of } \\
\text { bias }\end{array}$ & No \\
\hline $\begin{array}{l}\text { Funding sources of included studies } \\
\text { described }\end{array}$ & Yes \\
\hline $\begin{array}{l}\text { Appropriate methods used for } \\
\text { meta-analysis }\end{array}$ & Yes \\
\hline Impact of risk of bias assessed & $\begin{array}{l}\text { Risk of bias considered when } \\
\text { interpreting the results }\end{array}$ \\
\hline $\begin{array}{l}\text { Heterogeneity discussed (there was } \\
\text { no stically } \\
\text { Heterogeneity) }\end{array}$ & rignicant \\
\hline
\end{tabular}

\begin{tabular}{|l|l|}
\hline Publication bias assessed & No \\
\hline Conflicts of interest acknowledged & Yes \\
\hline
\end{tabular}

\section{Quality of included studies}

The overall quality of the included studies within the review was deemed to be of high quality (Mean PEDro score: 7). In all comparisons, except home-based exercise as compared to centrebased exercises for balance related activity (judged fair quality), the quality of evidence used was "good".

\section{Main review findings}

The review included 17 trials (published between 2005 and 2019) comparing home-based exercise versus usual care or placebo and four trials comparing home-based to centre-based exercise. The studies included were similar enough to allow a fixed effects meta-analyses to be used.

There was a small (SMD 0.3-0.5, Faraone 2008) statistically and clinically significant $(P=\leq 0.05)$ effect for home-based exercise compared to usual care or placebo for balance-related activities, gait speed immediately after intervention and $\mathrm{QOL}$ beyond the intervention period (quality of evidence good). However, there was no strong evidence that the intervention has an effect on Functional Reach test, QOL, Timed Get Up and Go test immediately after intervention or balancerelated activities beyond the intervention period compared to usual care or placebo (quality of evidence good)

When comparing home-based exercise versus centre-based exercise with equivalent exercise type and dose, there was not strong evidence that one mode of delivery is more effective than the other for balance-related activity and QOL, suggesting that the effects for these outcomes are similar for both modes of delivery (quality of evidence fair).

When indirectly comparing high-dose exercise (minimum $150 \mathrm{~min} /$ week for at least 6 weeks) compared to low-dose exercise (i.e. an average of 135 minutes of exercise a week for an average of 3.5 weeks) it was found that only high dose exercise produced a small statistically and clinically significant difference in balance-related activities when assessing home-based exercise against usual care or a placebo (quality of evidence good). For 
low dose exercise there was still uncertainty of its effect (quality of evidence good).

The influence of the level of supervision provided on the different outcomes remains unclear, as only minimally supervised sessions $(\leq 33 \%$ time supervised) produced a small statistically and clinically significant difference in balance-related activities when comparing home-based exercise versus usual care or a placebo (quality of evidence good). There was unclear evidence that the fully supervised (100\% time supervised) home-based exercise sessions had an effect (quality of evidence good).

\section{The main limitations of the review}

As acknowledged by the authors of the review within some of the comparisons, there were a limited number of trials available and a high proportion of the trials were relatively small.

\section{The authors and the journal}

The review team were from Australia based at the University of Sydney and the University of Canberra. The article was published in the Journal of Physiotherapy which has an impact factor of 5.5.

\section{Implications for practice and research}

This review found that home-based prescribed exercise improves balance, which reflects previous systematic review findings (Shea et al. 2017). It also improves gait speed, which was greater than had previously been reported, although the authors of this review considered that this might have depended on the type of exercise undertaken (Allen et al. 2011; Tomlinson et al. 2012). There was uncertainty on the effectiveness of exercise immediately following the intervention period for QOL. The authors of the review suggested that this could have been because of the exercise programs initially focusing on motor symptoms. However, the positive effect on QOL could be delayed as a small effect was found beyond the intervention period.

In people with mild to moderate Parkinson's disease, healthcare professionals can choose the location of the exercise based on the patient's preference, as the difference in outcomes between centre or home-based regimes may be minimal. There is still a need for further robust research in this area of location of delivery.
In a subgroup analysis exploring exercise dose, the review found that high-dose programmes improved balance related activities, while there is still uncertainty in regard to the effectiveness of lowdose exercise. Therefore, a minimum $150 \mathrm{~min} /$ week for at least 6 weeks would be recommended where applicable. There was some uncertainty regarding the level of supervision of sessions. There was substantial imprecision for fully supervised homebased exercise which made a direct comparison of level of supervision difficult. Therefore, further research is required around supervision comparing different levels.

It is possible to sustain a home-based exercise regime for people with Parkinson's disease, but without continuation of the intervention it is unclear what the long-term benefits for improving balancerelated activities would be. Supervisor Fulton different

Unfortunately, this review did not assess retention, adherence, cost and adverse events directly, even though these are important variables when weighing up the effectiveness of an intervention (Herbert et al. 2005). There is a need for further assessment of these variables for the use of a homebased exercise program with people with Parkinson's disease.

\section{CPD reflective questions}

-What are the methodological strengths and weaknesses of this review?

-What variables do you need to consider when prescribing a home-based exercise?

-Would you prescribe home-based exercise for a patient with Parkinson's disease?

- To what extent do costs and patient preferences determine which treatments are offered when review evidence suggests equivalence of clinical impact?

\section{References}

Allen NE, Sherrington C, Paul SS, Canning CG. 2011. Balance and falls in Parkinson's disease: a meta-analysis of the effect of exercise and motor training. Mov Disord. 26(9):1605-1615. eng. Bronte-Stewart HM, Minn AY, Rodrigues K, Buckley EL, Nashner LM. 2002. Postural instability in idiopathic Parkinson's disease: the role of medication and unilateral pallidotomy. Brain. 125(Pt 9):2100-2114. eng 
Canning CG, Sherrington C, Lord SR, Close JCT, Heritier S, Heller GZ, Howard K, Allen NE, Latt MD, Murray SM et al. 2015. Exercise for falls prevention in Parkinson disease: a randomized controlled trial. Neurology. 84(3):304-312. eng.

Faraone SV. 2008. Interpreting estimates of treatment effects: implications for managed care. P T. 33(12):700-711. Eng.

Flynn A, Allen NE, Dennis S, Canning CG, Preston E. 2019. Home-based prescribed exercise improves balance-related activities in people with Parkinson's disease and has benefits similar to centre-based exercise: a systematic review. Journal of Physiotherapy. 65(4):189-199.

Goodwin VA, Richards SH, Taylor RS, Taylor AH, Campbell JL. 2008. The effectiveness of exercise interventions for people with Parkinson's disease: A systematic review and meta-analysis. Movement Disorders. 23(5):631-640.

Kalia LV, Lang AE. 2015. Parkinson's disease. Lancet. 386(9996):896-912.

Herbert RJ, G. Mead, J. Birger Hagen, K. . 2005. Practical Evidence-Based Physiotherapy. Edinburgh. UK: Elsevier.

Klamroth S, Steib S, Devan S, Pfeifer K. 2016. Effects of Exercise Therapy on Postural Instability in Parkinson Disease: A Meta-analysis. J Neurol Phys Ther. 40(1):3-14.

Maher CG, Sherrington C, Herbert RD, Moseley AM, Elkins M. 2003. Reliability of the PEDro scale for rating quality of randomized controlled trials. Physical therapy. 83(8):713-721. eng.

Shea BJ, Reeves BC, Wells G, Thuku M, Hamel C, Moran J, Moher D, Tugwell $P$, Welch V, Kristjansson E et al. 2017. AMSTAR 2: a critical appraisal tool for systematic reviews that include randomised or non-randomised studies of healthcare interventions, or both. BMJ. 358:j4008.

Parkinson's UK, 2017. The incidence and prevalence of Parkinson's in the UK. Retrieved from:https://www.parkinsons.org.uk/sites/defau It/files/2018-

01/CS2960\%20Incidence\%20and\%20prevalence \%20report\%20branding\%20summary\%20report \%20Published\%202017.pdf

Shen X, Wong-Yu IS, Mak MK. 2016. Effects of Exercise on Falls, Balance, and Gait Ability in Parkinson's Disease: A Meta-analysis. Neurorehabil Neural Repair. 30(6):512-527.

Sveinbjornsdottir S. 2016. The clinical symptoms of Parkinson's disease. J Neurochem. 139 Suppl 1:318-324.

Tomlinson CL, Patel S, Meek C, Clarke CE, Stowe $\mathrm{R}$, Shah L, Sackley CM, Deane KHO, Herd CP,
Wheatley K et al. 2012. Physiotherapy versus placebo or no intervention in Parkinson's disease. Cochrane Database of Systematic Reviews. (8). Tysnes OB, Storstein A. 2017. Epidemiology of Parkinson's disease. J Neural Transm (Vienna). 124(8):901-905

This evidence summary is supported by the National Institute for Health Research (NIHR) Applied Health Research North West Coast (ARC NWC). The views expressed are those of the author(s) and not necessarily those of the NIHR or the Department of Health and Social Care. 